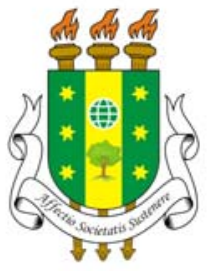

ZRBADM

Journal homepage:

www.arvore.org.br/seer

\section{UNIVERSIDADE ABERTA DO BRASIL: UMA AVALIAÇÃO DE ACESSIBILIDADE COM USUÁRIOS COM DEFICIÊNCIA VISUAL TOTAL E COM BAIXA VISÃO}

\section{RESUMO}

O programa institucional brasileiro chamado de Educação à Distância $(E a D)$ integra as agendas políticas federal e estaduais para a expansão e interiorização do ensino superior no Brasil. Seu alcance se deve, sobretudo, às tecnologias da informação, como a Internet, que são fundamentais à veiculação da educação à uma diversidade de grupos sociais dispersos pelo país. Nesse contexto, a Universidade Aberta do Brasil (UAB) desempenha um importante papel em articular as instituições de ensino superior e os governos estaduais e municipais a fim de atender o público local interessado por uma formação superior à distância. Tendo isto em vista, o acesso à informação em seu portal deve contemplar diferentes usuários, inclusive os deficientes visuais. A fim de verificar se o portal da UAB é acessível a este grupo, realizou-se uma pesquisa de caráter avaliativo, misto e exploratório, numa concepção pragmática, com a participação de pessoas com deficiência visual total e com baixa visão, bem como com validadores automáticos para identificar possíveis problemas de acessibilidade. Dentre os resultados alcançados, verificou-se que o portal não considerou a possibilidade de acesso desse grupo de usuários ao seu conteúdo. Ou seja, o portal não é acessível às pessoas com deficiência visual total e com baixa visão.

PALAVRAS-CHAVES: Acessibilidade na Web; Avaliação; Educação a Distância.

\section{UNIVERSIDADE ABERTA DO BRASIL: AN EVALUATION OF ACCESSIBILITY WITH USERS BLIND AND LOW VISION}

\section{ABSTRACT}

The Brazilian institutional program called Distance Education $(\mathrm{EaD})$ integrates the federal and state policy project whose objective is to expand and to introduce higher education to all interior places in Brazil. Its range is mainly due to information technologies such as the Internet, which are fundamental to the educational placement to a variety of social groups. In this context, the "Universidade Aberta do Brasil" (UAB) plays an important role in articulating higher education institutions and state and local governments to attend the local public interested in a higher distance education. With this, the access to information on its website should contemplate different users including the visually impaired. In order to check if the UAB portal is accessible to this group, there were mixed methods research and exploratory with the participation of people with visual disabilities full and low vision, as well as automatic validators to identify potential accessibility problems. Among the results, it was found that the portal did not consider the possibility that this group of users to access their content. In other words, the conclusion is that the portal is not accessible to people with visual disabilities full and low vision.

KEYWORDS: Web Accessibility; Evaluation; Distance Education.
Revista Brasileira de Administração Científica, Aquidabã, v.4, n.2, Ago 2013.

\section{ISSN 2179-684X}

\section{SECTION: Articles}

TOPIC: Sistemas e Tecnologia da Informação

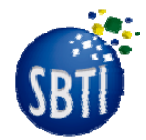

Anais do Simpósio Brasileiro de Tecnologia da Informação (SBTI 2013)

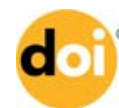

DOI: 10.6008/ESS2179-684X.2013.002.0019

Maria Laura da Costa Monteiro Universidade Federal de Pernambuco, Brasil http://lattes.cnpq.br/1699931886195496 lauramonterio16@hotmail.com

\section{Denis Silva da Silveira}

Universidade Federal de Pernambuco, Brasil http://lattes.cnpq.br/3799501798859187 dsilveira@ufpe.br

Simone Bacellar Leal Ferreira Universidade Federal do Rio Grande do Norte, Brasil http://lattes.cnpq.br/0926018459123736 simone@uniriotec.br

Received: 07/07/2013

Approved: 05/08/2013

Reviewed anonymously in the process of blind peer.

\section{Referencing this:}

MONTEIRO, M. L. C.; SILVEIRA, D. S.; FERREIRA, S. B. L.. Universidade Aberta do Brasil: uma avaliação de acessibilidade com usuários com deficiência visual total e com baixa visão. Revista Brasileira de Administração Cientifica, Aquidabã, v.4, n.2, p.273-289, 2013. DOI: http://dx.doi.org/10.6008/ESS2179684X.2013.002.0019 


\section{INTRODUÇÃO}

Comumente, a busca por informação representa um primeiro passo ao acesso e uso de bens e serviços tais como de educação, trabalho, saúde, lazer dentre outros. A informação é um elemento de fundamental importância, pois é por meio do intercâmbio informacional que os sujeitos sociais se comunicam e tomam conhecimento de seus direitos e deveres e, a partir deste momento, tomam decisões sobre suas vidas, seja de forma individual, seja de forma coletiva. Neste sentido, as organizações, ao capturar e distribuir a informação que dão suporte às suas atividades diárias internas e externas de seu público, possuem o desafio de desenvolver meios de comunicação que atendam às expectativas e às necessidades de todos os usuários (ARAÚJO, 1999; BAR-ILAN et al., 2009).

Atualmente, os portais nas organizações são utilizados, entre outras coisas, como principal meio de comunicação para disseminar parte de seu patrimônio informacional. Neste contexto, tais portais precisam ser planejados tendo em mente a existência de uma diversidade de grupos sociais que, independente de suas necessidades, possa obter as informações com um mínimo de dificuldades, inclusive, pelas pessoas com deficiência visual total e com baixa visão (JAEGER, 2006; BACH, 2009).

Embora seja uma estatística negativa, os usuários com deficiência visual total e com baixa visão compõem um grupo com expressiva representação dentre as pessoas com deficiência no Brasil. O número de indivíduos que se declarou como deficiente visual, no último censo demográfico, em 2010, corresponde a quase 36 milhões (os que não conseguem enxergar de modo algum, 528.624; possuem grande dificuldade, 6.056.684 e os que apresentam alguma dificuldade, 29.206.180) dentre os 45 milhões de brasileiros com deficiência (BRASIL, 2010). Para este público, a Internet tem se tornado um espaço de grandes possiblidades, conquistas e desafios. Pois, nem sempre, os portais estão acessíveis aos que possuem tal deficiência; contrariando, assim, o direito à informação e seu usufruto que Ihes são garantidos por lei. Desse modo, tem-se uma tarefa urgente e necessária: a de ampliar a criação de recursos para ação, comunicação, interação, desenvolvimento, inclusão digital e social de pessoas com necessidades especiais e disponibilizá-los nos espaços virtuais, visto que a Internet é uma rede que não é de ninguém, antes de todos (SANTAROSA et al., 2007).

Assim como outros grupos sociais, as pessoas com deficiência visual têm conquistado postos de trabalho, ocupando seu lugar na academia e em outras esferas da sociedade. Desse modo, é crescente o número de organizações que, em face da maior inserção destes grupos em sua força de trabalho, vêm se adaptando, tendo em vista estarem lidando com uma demanda diversificada de clientes à procura de bens e serviços que atendam às suas necessidades (FLEURY, 2000; ALVES; GALEÃO-SILVA, 2004; VERGARA; IRIGARAY, 2007). Nesse movimento, a busca de formação e de aperfeiçoamento dos grupos sociais sub-representados vai ao encontro da atual conjuntura de expansão e democratização da educação superior, levando as 
universidades a abrirem suas portas para a diversidade. Neste cenário, a Universidade Aberta do Brasil (UAB) tem sido responsável por agregar as universidades e os institutos públicos, em todo o país, em prol de uma maior oferta de formação superior à distância para professores da educação básica pública, prioritariamente; mas também para dirigentes, gestores e outros profissionais (BRASIL, 2012).

A Universidade Aberta do Brasil não é um local físico, mas um sistema de informação, criado pelo Ministério da Educação, em 2005, no âmbito do Fórum das Estatais pela Educação. Este Sistema Nacional de Ensino Superior à Distância com a parceria de Universidades Públicas Federais, Estaduais e Institutos Federais de Educação, Ciência e Tecnologia, por meio de consórcios com municípios e estados, oferece cursos de bacharelados, licenciaturas, tecnólogos e especializações (BRASIL, 2012). Em 2006, o programa UAB foi oficializado por meio do Decreto $\mathrm{n}^{\circ}$ 5.800. Atualmente, 103 instituições estão integradas pelo sistema UAB que conta com 636 polos de apoio presencial, com maior concentração nas regiões Norte e Nordeste do país (BRASIL, 2012). Ainda de acordo com o último balanço de 2012, a Coordenação de Aperfeiçoamento de Pessoal de Nível Superior (CAPES) apresenta o alcance de números extremamente representativos para o sistema, como as mais de 140 mil matrículas nos cursos de licenciatura; 24.207 no bacharelado; mais de 6.877 no nível tecnólogo; mais de 66 mil nas especializações; 21.176 para aperfeiçoamento e 2.800 no Mestrado Profissional em Matemática em Rede Nacional (PROFMAT). Reunindo também os cursos de formação pedagógica, extensão e sequencial, totalizam-se 268.028 matrículas ativas em outubro de 2012 e 42.611 concluintes até este período (BRASIL, 2012).

Com a UAB, a prática da "abertura" em sistemas de educação incentiva à adoção de medidas voltadas à aceitação de alunos de várias condições físicas e sociais, com faixa etária e propósitos diferentes (SANTOS, 2009). Pois, "em princípio, o público da educação a distância é ilimitado" (MAIA; MATTAR, 2007, p. 9). Sendo assim, as pessoas com deficiência visual precisam ser consideradas como potenciais usuárias da Internet e alunas de EaD; posto que uma das características mais contundentes desta modalidade é o autoaprendizado de jovens e adultos, cuja acessibilidade ao sistema educacional se faz a qualquer hora e lugar (BELLONI, 2009).

Para contato com o público, o sistema UAB dispõe de um portal (http://www.uab.capes.gov.br/) que é voltado às instituições de ensino superior, aos estudantes, gestores, professores e ao público em geral. Tendo isso em mente, pergunta-se: como se dá o acesso à informação no portal da UAB por pessoas com deficiência visual total e com baixa visão?

O objetivo deste artigo é identificar possíveis problemas de acesso à informação, por meio do portal da UAB. Tendo em vista, como Bach (2009) destaca, entre os cidadãos com problemas graves de acessibilidade na web, encontram-se os deficientes visuais, uma vez que a informação disponível, em grande parte, é visual. Fato que acarreta dificuldades de acessibilidade, especialmente, às pessoas com deficiência no tocante ao uso de programas de leitura de tela que 
se encarrega de converter em voz os textos publicados na Internet (SILVEIRA et al., 2010). A fim de alcançar o objetivo proposto, fez-se uma pesquisa, de caráter avaliativo, misto e exploratório, com a participação de pessoas com deficiência visual total e com baixa visão e por meio de dois validadores automáticos, o DaSilva e o Hera.

O presente artigo encontra-se estruturado em seis partes: a primeira corresponde ao referencial teórico acerca da acessibilidade. Em seguida, são apresentados todos os procedimentos metodológicos necessários à avaliação. A terceira parte inclui uma descrição do objeto de pesquisa, do modo como foi realizada a avaliação. Na sequência, mostram-se os resultados da avaliação com os validadores automáticos DaSilva e o Hera, bem como àqueles alcançados com a participação dos usuários com cegueira total e com baixa visão. Por fim, restam algumas discussões e conclusões.

\section{REVISÃO TEÓRICA}

A pesquisa bibliográfica sumariza as principais contribuições teóricas acerca do acesso à informação e da acessibilidade web, bem como apresenta trabalhos semelhantes empreendidos em portais públicos com a participação de usuários.

\section{Acessibilidade Web}

A informação é um direito constitucional que, para ser garantido a todos os cidadãos, fazse necessário o provimento de meios e de condições para efetivar o acesso (CEPIK, 2000). O acesso e o uso da informação são condições necessárias à construção da cidadania. Do contrário, pode-se dizer que o "não-acesso à informação ou ainda o acesso limitado ou o acesso a informações distorcidas dificultam o exercício pleno da cidadania" (ARAÚJO, 1999, p. 155). Hoje, graças aos avanços tecnológicos em informação e comunicação, a Internet tem sido um dos principais meios de acesso à informação. E para que todos usufruam das informações veiculadas na web, estas precisam ter um mínimo de restrições de acesso (BABU et al., 2010).

Nesse contexto, o emprego da expressão "acessibilidade na web" refere-se à possibilidade de qualquer pessoa poder usar a Internet, bem como Sistemas de Informação, a despeito de suas capacidades físico-motoras, perceptivas, sociais e culturais (FERREIRA; NUNES, 2008; SILVEIRA et al., 2010; CAPRA et al., 2011).

Para Barbosa e Silva (2010), a acessibilidade é um critério de qualidade de Interação Humano-Computador que está relacionado com a capacidade de o usuário acessar o sistema a fim de interagir com o mesmo, sem que a interface apresente obstáculos que inviabilize tal interação. Também refere-se ao desenvolvimento de sites e de softwares flexíveis o bastante para atender às necessidades de diferentes usuários, de preferências e em situações diversas. Faz 
alusão também ao direito de inclusão social; independente de capacidades físicas, distância geográfica, língua ou quaisquer fatores (FREIRE, 2008).

Nesse sentido, as organizações públicas e privadas precisam oferecer portais acessíveis com a finalidade de atender a qualquer pessoa e garantir-lhe o direito à informação. A promoção da acessibilidade, assim, requer que um projeto de interface preveja restrições tecnológicas e deficiências dos usuários (FREIRE, 2008; BACH, 2009).

Todavia, apesar da instituição de leis que regulamentam a disponibilização de conteúdo acessível em sites de órgãos públicos brasileiros, desde 2004, por força do Decreto $\mathrm{n}^{\circ} 5.296 \mathrm{e}$ dos mesmos apresentarem selos de certificação, nem sempre suas páginas são acessíveis quando avaliadas com a participação do próprio usuário. A literatura especializada aborda essencialmente a avaliação feita automaticamente; a realizada por especialistas e a empreendida com a participação de usuários com algum tipo de deficiência ou limitação. Porém, ressalva-se que esta última detecta barreiras que são imperceptíveis aos métodos anteriores. Sendo, assim, recomendada a avaliação realizada com a combinação entre métodos (BACH et al., 2008; $\mathrm{BACH}$, 2009; SILVEIRA et al., 2010; LIMA et al., 2010; CAPRA et al., 2011).

\section{Trabalhos Relacionados}

Com base na literatura especializada, é possível identificar alguns trabalhos que defendem a avaliação de acessibilidade com a participação de pessoas com deficiência visual. Lima et al. (2010) fizeram um estudo exploratório, realizando uma avaliação dos sites da UOL e do TERRA com pessoas com deficiência visual total, cujo objetivo foi avaliar como os tais interagiam com o sistema; em especial os sistemas computacionais de comunicação. O estudo resultou na identificação de problemas que podem dificultar ou impedir o acesso, bem como gerou recomendações para que os sistemas em foco possam ser mais acessiveis e de fácil uso para o grupo em estudo. Já Silveira et al. (2010) empreenderam uma avaliação no site da Receita Federal com o objetivo de identificar problemas que viessem a impedir ou dificultar tanto o acesso quanto o entendimento da informação por pessoas com deficiência visual total. Eles puderam observar o modo de interação com o site, assim como as dificuldades enfrentadas. Perceberam, por conseguinte, a real importância da participação do usuário no desenvolvimento de sites, na qualidade de testador, ao lado de validadores automáticos; a fim de se obter um grau mais elevado de acessibilidade.

\section{MATERIAIS E MÉTODOS}

O propósito desta pesquisa de métodos mistos concomitantes, numa concepção pragmática (FLICK, 2009; CRESWELL, 2010) é verificar como se dá o acesso à informação no portal da UAB por pessoas com deficiência visual total e com baixa visão. Para tanto, foi realizada 
uma avaliação de caráter quantitativo com validadores automáticos e outra avaliação com a participação de tais usuários para a coleta de dados qualitativos e quantitativos, para analisar os resultados de modo comparativo.

Assim, a investigação foi realizada a partir das seguintes etapas: (1) escolha dos usuários participantes da pesquisa; (2) estabelecimento dos métodos de coletas de dados; (3) definição das tarefas; (4) realização de uma avaliação preliminar; (5) avaliação e análise com validadores automáticos; e (6) avaliação e análise com os usuários participantes.

\section{Escolha dos Usuários Participantes}

A escolha dos usuários participantes deu-se em conformidade com as recomendações de Nielsen (1993) para as quais é suficiente a participação de cinco usuários para avaliação de usabilidade; propondo-se o mesmo com foco na acessibilidade (BARBOSA; SILVA, 2010), uma vez que ao exceder esse número, a curva é decrescente em termos de novos dados. Dessa forma, foram selecionados cinco participantes com deficiência visual total e com baixa visão e um sexto para o teste preliminar.

Contudo, além da quantidade de usuários com tais deficiências, procurou-se identificar pessoas que também já tivessem experiência em navegação na web com leitores de tela. Todos os usuários foram contatados por meio do Instituto dos Cegos da Paraíba Adalgisa Cunha (ICPAC), localizado na cidade de João Pessoa-PB.

Com base no questionário aplicado, levantaram-se as principais características do perfil dos participantes, elencadas na Tabela 1.

Tabela 1: Principais Características dos Usuários Participantes da Avaliação.

\begin{tabular}{l|l|l|l}
\hline $\begin{array}{l}\text { Usuário(a)/ } \\
\text { deficiência }\end{array}$ & $\begin{array}{l}\text { Idade/ } \\
\text { Sexo }\end{array}$ & Experiência com Leitores de Telas & Ocupação \\
\hline $\begin{array}{l}\text { Teste-piloto cegueira } \\
\text { total }\end{array}$ & $19 / \mathrm{M}$ & 10 anos com Jaws e Dosvox & Aluno do Liceu Paraibano e do ICPAC \\
\hline $1^{\circ}$ cegueira total & $32 / \mathrm{M}$ & 9 anos com Jaws e NVDA & Professor do IFPB e do ICPAC \\
\hline $2^{\circ}$ cegueira total & $18 / \mathrm{M}$ & $\begin{array}{l}\text { Mais de } 10 \text { anos com Jaws, NVDA e } \\
\text { Dosvox }\end{array}$ & $\begin{array}{l}\text { Aluno concluinte do SESC Centenário e } \\
\text { do ICPAC }\end{array}$ \\
\hline $3^{\text {a } \text { baixa visão }}$ & $26 / \mathrm{F}$ & 3 anos com o Jaws & Professora do ICPAC \\
\hline $4^{\text {a }}$ baixa visão & $19 / \mathrm{F}$ & 2 anos com o Jaws e NVDA & Aluna do ICPAC \\
\hline $5^{\mathrm{a}}$ cegueira total & $19 / \mathrm{F}$ & 6 anos com o Dosvox & Aluna do IFPB e do ICPAC \\
\hline
\end{tabular}

\section{Definição dos Métodos de Coleta de Dados}

Para a coleta dos dados quantitativos, as páginas representativas do portal foram submetidas à análise por meio das ferramentas Hera e Da Silva. No tocante aos dados qualitativos e ainda quantitativos (como o tempo médio da avaliação), procederam-se observações, entrevistas e aplicação de questionários realizados em ambiente natural de uso de hardware e software, familiares aos participantes. 


\section{Definição das Tarefas}

A definição e a sequência das tarefas foram estabelecidas conforme as páginas selecionadas que representam o percurso para efetuar o contato virtual entre o usuário e a UAB. Como no portal encontra-se apenas a recomendação de que os cursos à distância prevejam o atendimento de necessidades especiais em seus Projetos Políticos Pedagógicos, sem maiores informações, supôs-se que as mesmas poderiam ser obtidas pelo contato virtual, e que o próprio portal daria condições básicas de acesso ao deficiente visual. Nesse sentido, foram definidas as tarefas conforme as figuras a seguir. A Figura 1 ilustra a página principal do portal da UAB.

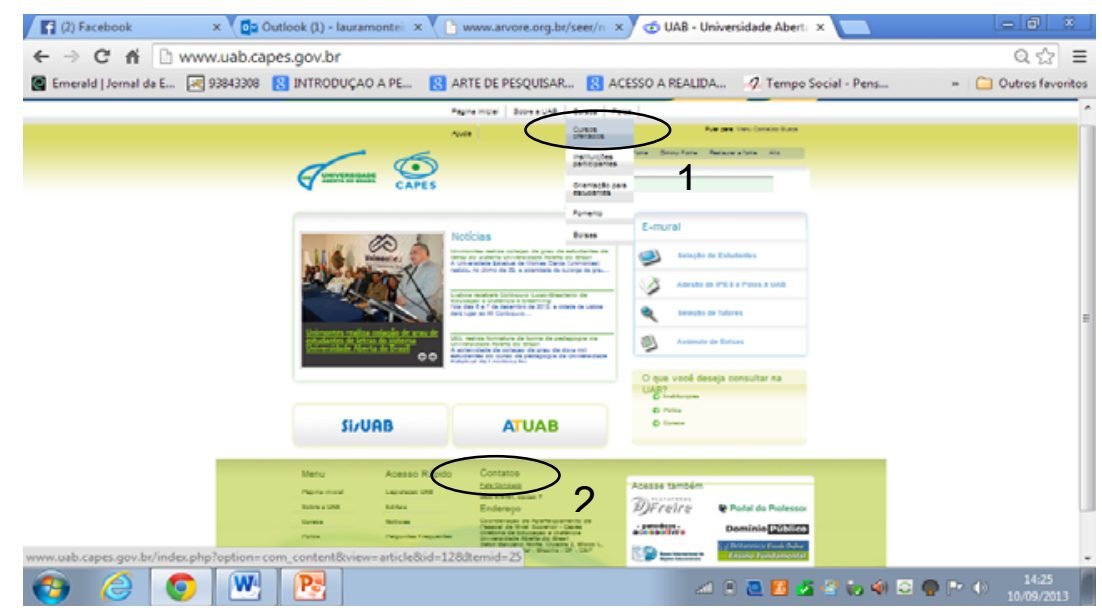

Figura 1: Página Principal do Portal da UAB. Fonte: http://www.uab.capes.gov.br.

Ao acessar o portal, o usuário tinha como primeira tarefa encontrar o link Cursos Ofertados, disponível no interior de um combobox, em destaque na Figura 1. Esta atividade teve como objetivo familiarizar o usuário com a oferta de cursos superiores pelo sistema UAB para que, na solicitação de informações, pudesse referir-se a um curso que possivelmente fosse de seu interesse. Vale ressaltar, que o teste realizado no portal simula uma demanda de informação de interesse da pesquisa, não necessariamente do participante.

Ainda na homepage, o usuário teve como segunda tarefa a identificação do link Fale conosco em Contatos, no local indicado pelo destaque na Figura 1. Este link, quando acessado, conduziria o participante à outra página. Fora da homepage, o usuário iniciaria a terceira tarefa. $\mathrm{O}$ portal oferece duas opções de acesso a contatos virtuais: a primeira corresponde ao link da Universidade Aberta do Brasil (UAB) e a segunda refere-se a Bolsas UAB. O ambiente também oferece outra opção que seria a de acompanhar "demandas já enviadas". Neste momento, foi determinada ao usuário a escolha da primeira, conforme demonstrado na Figura 2.

Dessa forma, ao usuário, conduzido à segunda página fora da homepage do portal, foi solicitado o preenchimento do formulário de contato, denominado "Abertura de demanda", o que corresponde à quarta tarefa ilustrada pela Figura 3. Considerou-se suficiente à avaliação realizada neste estudo, o preenchimento apenas dos campos obrigatórios, identificados por asteriscos na cor vermelha. 


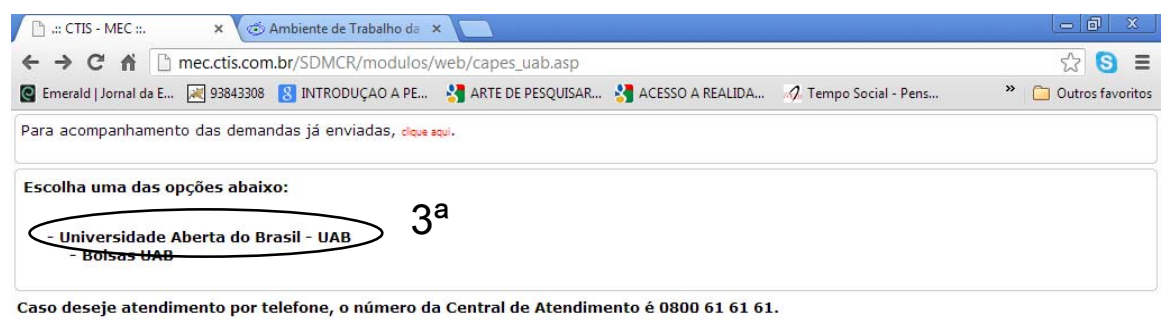

Figura 2: Opções de Acesso Virtual e Por Telefone da UAB. Fonte: http://www.uab.capes.gov.br.

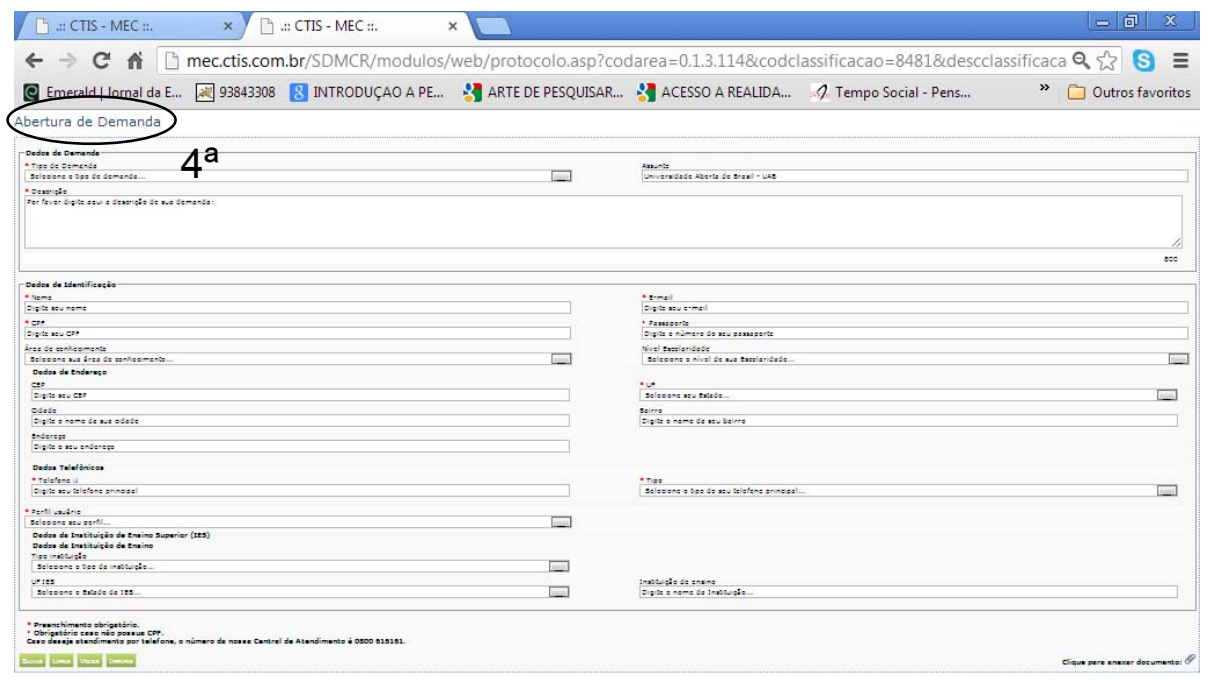

Figura 3: Formulário de contato virtual da UAB. Fonte: http://www.uab.capes.gov.br.

Finalmente, a quinta tarefa correspondeu ao reconhecimento do feedback de envio do formulário à UAB. Findo o contato, o portal informa se a atividade foi realizada com sucesso (Figura 4) e o emissário recebe também uma mensagem eletrônica em seu e-mail, confirmando a realização do contato virtual.

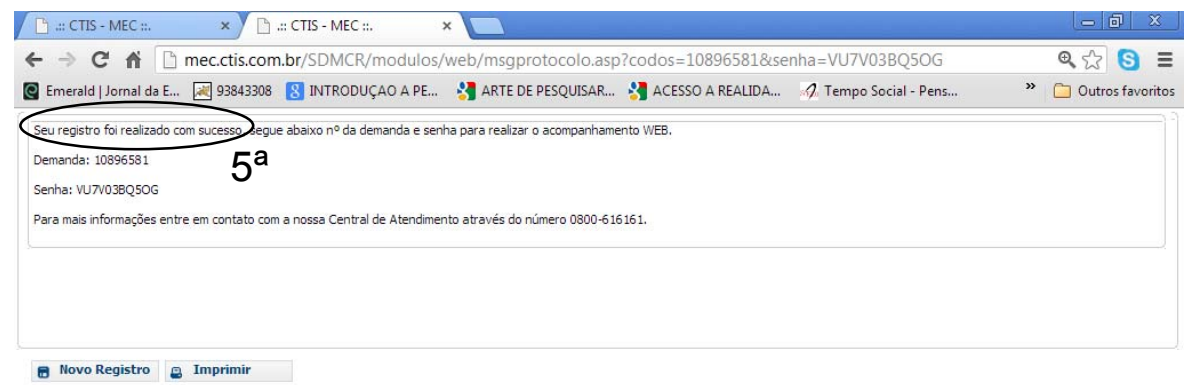

Figura 4: Feedback de envio do formulário à UAB. Fonte: http://www.uab.capes.gov.br.

\section{Realização de uma Avaliação Preliminar}

Segundo Nielsen (1993), não deve ser feito nenhuma avaliação de usabilidade sem antes realizar um pré-teste (teste piloto). Neste sentido, em avaliações de acessibilidade também se adota tal recomendação com o objetivo de identificar possíveis problemas e questões importantes, 
antecipadamente, à avaliação com os cinco usuários. Procurou-se perceber quais seriam os aspectos mais relevantes à execução da avaliação, outrora listados por Bach et al. (2009) que pudessem ser evidenciados nesse estudo e a identificação de outros com algumas modificações.

Os principais objetivos com a avaliação preliminar foram: (1) testar a habilidade da pesquisadora em executar o teste por meio da observação e registro das ações predeterminadas; (2) familiarizar a mesma com a descrição feita pelo leitor de tela; (3) verificar a qualidade da gravação em áudio; (4) evidenciar se as tarefas, o questionário e o roteiro de entrevista estavam claros; (5) perceber se o tempo estimado seria viável à realização das tarefas; (6) verificar se a verbalização simultânea ou consecutiva à execução das tarefas seria possível; e (7) confirmar a viabilidade de ser realizada nas residências dos usuários e nas dependências do Instituto Federal de Educação, Ciência e Tecnologia - IFPB como locais para a avaliação.

Como resultado da avaliação preliminar, foi possível confirmar a maioria dos objetivos. Apenas o tempo não foi suficiente. Esperava-se que entre 10 e 15 minutos o usuário cumprisse o roteiro de tarefas, haja vista ser relativamente simples. Todavia, levaram-se 31 minutos em média para este fim. Os resultados referentes ao teste de acessibilidade do portal com este usuário serão apresentados com os demais na subseção 5.2 .

\section{Avaliação com Validadores Automáticos}

Os validadores automáticos são softwares voltados à verificação de acessibilidade de websites, a fim de demonstrarem se o mesmo está em conformidade com as diretrizes de acessibilidade por meio da sintaxe das páginas, como as da WCAG (Web Content Accessibility Guidelines) do W3C (World Wide Web Consortium) e as do Modelo de Acessibilidade Brasileiro (e-MAG) (BACH, 2009). Para a avaliação de acessibilidade do portal, optaram-se pelos validadores DaSilva (http://www.dasilva.org.br/) e o Hera (http://www.sidar.org/hera/index.php.pt) que avaliaram todas as páginas referentes às tarefas. A escolha se deu porque as diretrizes WCAG 1.0 do W3C ainda são as principais referências mundiais (FREIRE, 2008).

Todavia, Bach (2009) afirma que não se pode concluir que um site é acessível apenas pela avaliação automática; pois estar adequado do ponto de vista dos validadores não quer dizer que o mesmo esteja acessível a qualquer usuário, necessitando, assim, de revisão humana. Os resultados aos quais os validadores chegaram, estão descritos no subitem 4.1.

\section{Avaliação com os Usuários Participantes}

Buscou-se um perfil de participantes mais coerente ao público, ao qual se volta também a UAB, como pré-vestibulandos e professores. Os motivos da escolha destes possuem duas razões: a primeira se dá pelo fato do teste ser também uma oportunidade dos usuários entrarem em contato com a UAB; de modo que solicitem informações sobre o atendimento de suas 
necessidades pelas instituições de ensino superior e conheçam os cursos que são oferecidos. Estes, principalmente, para professores e outros profissionais. A outra razão condiz com o público que frequenta o Instituto dos Cegos Adalgisa Cunha, composto em grande parte por jovens estudantes e professores. Os resultados referentes à avaliação com os usuários estão descritos no subitem 4.2 .

\section{Avaliação do Portal UAB}

As avaliações foram conduzidas em ambientes naturais de uso. Três delas realizadas na residência dos participantes, efetivadas por meio dos computadores de uso pessoal dos mesmos, através dos navegadores Internet Explorer e Google Chrome; e com o auxílio dos leitores de telas Jaws e Dosvox. Com os demais participantes, o teste do portal foi feito no IFPB (http://www.ifpb.edu.br/), situado na Av. $1^{\circ}$ de Maio, 720, bairro do Jaguaribe, em João Pessoa PB. Neste, os usuários utilizaram um netbook destinado aos alunos e aos professores deficientes visuais, no qual se encontram instalados os leitores Dosvox e Jaws. O navegador escolhido foi o Internet Explorer.

De acordo com os integrantes, os locais em que eles acessam a Internet com mais frequência são a casa, o trabalho e nos respectivos institutos ICPAC e IFPB. O interesse de acesso se dá, principalmente, sobre pesquisas escolares; para baixar programas; visitar redes sociais; checar e-mails e estar em dia com o noticiário. Relataram que a Internet constitui um importante meio de informação e comunicação para sua vida diária; pois através dela estão conectados com o mundo e, principalmente, porque permite que tenham mais autonomia. Como visto, todos possuem experiência, acima de dois anos, com leitores de tela.

\section{RESULTADOS}

Esta parte do trabalho contém a descrição e a análise dos resultados da referida avaliação, em conformidade com o objeto pretendido, que fora identificar os problemas de acesso à informação virtual no portal da UAB, por meio de validadores automáticos e com a participação de pessoas com deficiência visual e com baixa visão. Primeiramente, apresentar-se-ão os resultados obtidos com os validadores automáticos, o DaSilva e o Hera. Em seguida, os achados referentes à avaliação com os usuários.

\section{Segundo os Validadores Automáticos}

Todas as páginas que compõem o trajeto das tarefas estabelecidas foram avaliadas pelos validadores. Deve-se esclarecer que o DaSilva tanto fornece o número de erros distribuídos por Prioridades 1, 2 e 3 quanto acusa a frequência de ocorrência dos tais erros no portal - valores 
entre parênteses, verificados na Tabela 2. Já o Hera só fornece a quantidade de erros classificados de acordo com as Prioridades estabelecidas pelo WCAG 1.0.

Tabela 2: Erros Identificados pelos Validadores Da Silva e Hera.

\begin{tabular}{|c|c|c|c|c|c|c|c|c|}
\hline & \multicolumn{2}{|c|}{ Tarefas 1 e 2} & \multicolumn{2}{|c|}{ Tarefa 3} & \multicolumn{2}{|c|}{ Tarefa 4} & \multicolumn{2}{|c|}{ Tarefa 5} \\
\hline Nível & 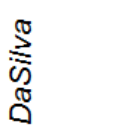 & $\frac{\pi}{\Phi}$ & 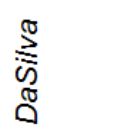 & $\frac{\pi}{\frac{\pi}{2}}$ & $\begin{array}{l}\stackrel{\pi}{\mathbb{W}} \\
\underset{\mathbb{N}}{0}\end{array}$ & $\frac{\pi}{\Phi}$ & 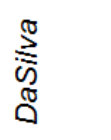 & $\frac{\pi}{\Phi}$ \\
\hline Prioridade 1 & $13(127)$ & 3 & $19(62)$ & 2 & $0(44)$ & 0 & $15(42)$ & 1 \\
\hline Prioridade 2 & $4(26)$ & 7 & $14(19)$ & 10 & $1(33)$ & 0 & $8(8)$ & 8 \\
\hline Prioridade 3 & $0(86)$ & 2 & $0(12)$ & 4 & $0(18)$ & 2 & $0(9)$ & 2 \\
\hline Total & 17 & 12 & 33 & 16 & 1 & 2 & 23 & 11 \\
\hline
\end{tabular}

Como se pode observar, as páginas do portal da UAB, representadas pelas tarefas em destaque, apresentaram 47 erros graves de Prioridade 1, segundo o DaSilva; enquanto para o Hera apenas 6 erros foram percebidos em sua totalidade. Conforme as diretrizes WCAG 1.0, isto pode implicar na impossibilidade de acesso ao seu conteúdo. Em outras palavras, as páginas correspondentes às tarefas de 1 a 5 são inacessíveis a um ou mais grupo de usuários, conforme os validadores. Entre os erros encontrados, destacou-se a falta de equivalente textual para cada elemento não textual. Portanto, recomenda-se que ao ser atualizado o conteúdo dinâmico, seja feito o mesmo com o conteúdo equivalente textual.

No tocante à Prioridade 2, verificou-se a existência de 27 erros na avaliação do DaSilva e 25 erros para o Hera que podem dificultar o acesso à informação na web. Já os erros de Prioridade 3 são aqueles que as normas e recomendações de acessibilidade elencam e que podem ser revistos para facilitar o acesso a documentos na web. Ao passo que o DaSilva não percebeu nenhum, o Hera apresentou o total de 10 erros.

Uma observação a ser feita é a discrepância entre os erros de Prioridade 1 no total das páginas avaliadas (47 versus 6), encontrados pelo DaSilva e pelo Hera, respectivamente, que podem indicar a fragilidade de uma avaliação de acessibilidade apenas apoiada por ferramentas automáticas. Isto aponta para a necessidade da participação de usuários. Outro problema evidenciado por estes validadores refere-se à descrição dos problemas a qual não se faz de modo claro e nem de fácil compreensão por leigos.

\section{Avaliação com os Usuários}

No conjunto das avaliações, algumas considerações gerais podem ser feitas a partir dos comentários dos usuários. A primeira delas é a de que todos eles desconheciam o portal da UAB, assim como não ouviram falar do próprio programa. A outra diz respeito ao primeiro contato com o portal, por meio da sua homepage. Afirmaram que a mesma possuía um conteúdo enxuto e sem muitos links, facilitando a navegação. Relataram que quando se deparam com uma página "poluída" com excesso de imagens, de links e de informações, no mínimo, o acesso é cansativo, 
confuso. Por vezes, desistem ou pedem ajuda ao não conseguirem acessar as informações desejadas; já que os leitores de telas não leem todas as informações e/ou não abrem todos links. Tendo dito isto, por meio da experiência e do relato de cada usuário, perceber-se-ão os aspectos que mais dificultaram a realização das tarefas ou impediram a consecução das mesmas.

Em sua residência, o usuário a realizar o teste-piloto do portal considerou as páginas, nas quais executou as tarefas 1, 2 e 3, acessíveis. Comentou que não sentiu dificuldade alguma em encontrar o link Cursos, ofertado no interior de um combobox, e que a redação dos cursos estava clara. Após a leitura, teve que retornar ao conteúdo da homepage para encontrar e acessar o link de Contato Fale Conosco, sendo conduzido, assim, à outra página na qual escolheu o link Universidade Aberta do Brasil - UAB, de modo ágil. Contudo, ao se deparar com o formulário denominado "Abertura de Demanda" na página seguinte, a princípio não compreendeu o que significava tal expressão e sua finalidade. Como já lhe havia explicado, o formulário seria preenchido apenas nos campos obrigatórios, visualmente identificados por um asterisco vermelho. Dessa forma, ao percorrer três vezes todo o formulário, disse: "o Jaws não diferencia os campos obrigatórios dos que não são" (1 usuário). Comentou, então, que só realizaria a quarta tarefa com a ajuda da pesquisadora. Por conseguinte, forneceu as informações, mas ao tentar finalizar, foi impedido por conta de um erro no número do CPF. No entanto, o leitor só informava que o erro estava "destacado", ou seja, em negrito e na cor vermelha, logo abaixo do campo. Não informando, contudo, qual tinha sido o erro. O usuário resolveu usar o Dosvox, retomando o preenchimento desde o início. O leitor indicou os campos obrigatórios e onde estava o erro, mas não leu o link Salvar para finalizar a tarefa. Com isso, ele desistiu após 31 minutos decorridos do primeiro comando no portal.

O primeiro participante é professor do IFPB. Faz uso da Internet com mais frequência para baixar programas. Para o teste, utilizou o navegador Internet Explorer e o leitor Jaws. Foi observado o desconforto em utilizar o netbook do Instituto, decorrente da falta de uso frequente. A primeira tarefa foi executada sem dificuldades, mas demorou encontrar o link Fale Conosco, solicitando ajuda para isso, ao passo que comentou: "considero cansativo ter que ouvir toda a página para encontrar o que quero" ( $2^{\circ}$ usuário). A terceira tarefa foi feita a contento. Porém, quando se deparou com o formulário, logo percebeu que o leitor não lhe guiaria apenas pelos campos obrigatórios. Assim como o primeiro usuário, solicitou ajuda, ao invés de preencher todos os campos, caso optasse por fazê-lo. Outro problema identificado pelo usuário se refere à seta no interior e à direita, no campo para selecionar informações alternativas. Os usuários se locomovem pelo portal utilizando as setas de direção do teclado ou com o Tab. Quando ele tentava acionar a lista de informação dentro do campo com ambos os mecanismos, o cursor saía do mesmo, indo para outros espaços, o que se repetiu por várias vezes. Só foi possível a execução da tarefa com a ajuda da pesquisadora. Finalmente, conseguiu salvar as informações, indo para a última página. O Jaws indicou que a solicitação de informação foi "realizada com sucesso". Porém, o participante 
não compreendeu para que serviriam o número da demanda e a senha fornecidos. Completou todo o teste em 35 minutos.

Ainda no IFPB, o segundo participante, por sua vez, também fez uso do navegador Internet Explorer e do leitor Jaws no início da tarefa. Concluiu as tarefas 1, 2 e 3 com sucesso. Mas, no tocante ao formulário, também evidenciou os problemas já descritos. Com ajuda, informou os dados; porém ao tentar salvá-los, novamente um erro no número de telefone o impediu. O leitor não o avisou que era necessário digitar primeiro o DDD entre parênteses. Decidiu, então, retomar toda a tarefa pelo Dosvox , finalizando-a. O usuário levou 37 minutos para concluir as tarefas. Conclui afirmando: "é necessário resolver os problemas no portal, já que não tive quase autonomia para estabelecer o contato virtual" ( $3^{\circ}$ usuário).

A terceira participante possui baixa visão e é professora do ICPAC. Formada em Pedagogia, por conta dos trabalhos acadêmicos, resolveu há três anos aprender a usar a Internet com o leitor Jaws, dependendo dele para navegar. O teste foi em sua casa e levou 25 minutos. As primeiras tarefas foram executadas com rapidez. Ela demorou a perceber quais eram as informações obrigatórias, pois o Jaws não Ihe informou. Ao se aproximar do monitor, reconheceu os campos em destaque. Mas, perguntou se algum dos outros usuários havia conseguido fornecer os dados, conforme estava sendo solicitado. Considerou, pois, que "o contato virtual da UAB é totalmente inacessível à pessoa com deficiência visual total" ( $3^{\mathrm{a}}$ usuária). Na quinta tarefa, ela estranhou o fato do portal vincular o acompanhamento da demanda em seu domínio, por meio de senha. Disse ela: "ficaria mais prático se as informações fossem enviadas para o e-mail do solicitante, já que a sua checagem se dá de modo mais frequente" ( $3^{a}$ usuária). Foi a única participante totalmente autônoma na consecução das tarefas.

O teste seguinte com a quarta participante se deu em sua residência. Assim que o portal foi acessado, ela buscou "aumentar a fonte" na homepage. No entanto, apenas alguns conteúdos foram ampliados por este recurso, ficando ilegíveis para ela os links Cursos ofertados e Fale Conosco. Com o auxilio do Jaws, a usuária executou as tarefas 1, 2 e 3 com tranquilidade. Já na página do contato virtual, o leitor mais uma vez não diferenciou os campos de preenchimento obrigatório. Dessa forma, a usuária decidiu informar os dados em todos os campos, o que levou mais tempo, cerca de 38 minutos, pois o cursor não obedecia ao comando das setas ou do Tab para abrir a lista de opções de informação dentro dos campos. A aluna do ICPAC concluiu que "o contato virtual pelo formulário não é acessível para pessoas com deficiência visual, uma vez que os leitores de telas são limitados e quanto mais simples forem os mecanismos de comunicação, melhor será a acessibilidade" ( $4^{\mathrm{a}}$ usuária).

Finalmente, a quinta participante optou em usar o Dosvox e o navegador Internet Explorer do netbook do IFPB. De modo semelhante aos demais, não teve grandes dificuldades em executar as tarefas 1, 2 e 3. Diante do formulário, não entendeu a solicitação das primeiras informações, ficando confusa, por exemplo, com o "Assunto: Universidade Aberta do Brasil UAB". Ao se deparar com as setas no canto do campo, demonstrou impaciência por conta do 
cursor que saía ao invés de listar as alternativas de preenchimento. Então, pediu ajuda ao segundo participante para que ele the guiasse nas informações. Mesmo assim, a participante decidiu desistir aos 20 minutos, afirmando que o formulário deveria ser mais simples. Diante do exposto, no Quadro 1 foram sumarizados os resultados aqui descritos.

Quadro 1: Resultados da avaliação envolvendo os usuários.

\begin{tabular}{|l|l|}
\hline $\begin{array}{l}\text { Redação da oferta dos } \\
\text { cursos (parte da tarefa }\end{array}$ & Linguagem clara e objetiva considerada por todos. \\
\hline $\begin{array}{l}\text { Acesso aos links } \\
\text { (tarefas 1, 2 e 3) }\end{array}$ & $\begin{array}{l}\text { Realizado sem grandes dificuldades. Mas, com o uso do zoom o conteúdo ficou distorcido e } \\
\text { os links (Cursos ofertados e Fale conosco) permaneceram ilegíveis a uma das participantes } \\
\text { com baixa visão. }\end{array}$ \\
\hline $\begin{array}{l}\text { Formulário de abertura } \\
\text { de demanda (tarefa 4) }\end{array}$ & $\begin{array}{l}\text { Foi considerado complexo e inacessível por condicionar o preenchimento dos campos } \\
\text { obrigatórios e a percepção de erros aos símbolos e às cores. Além disso, constatou-se que } \\
\text { a lista de informações alternativas no interior e à direita dos campos (indicada e acessada } \\
\text { por uma seta) não responde aos comandos de direção e impossibilita salvar o formulário, já } \\
\text { que um dos leitores de tela não identificou tal alternativa. }\end{array}$ \\
\hline $\begin{array}{l}\text { Feedback de envio } \\
\text { (tarefa 5) }\end{array}$ & Reconhecido com autonomia apenas por um usuário com baixa visão. \\
\hline $\begin{array}{l}\text { Acompanhamento da } \\
\text { demanda por } \\
\text { informações }\end{array}$ & $\begin{array}{l}\text { Foi criticado o acompanhamento no domínio do portal, pois seria mais acessível se fosse } \\
\text { enviado ao e-mail do demandante. }\end{array}$ \\
\hline $\begin{array}{l}\text { Tempo de realização } \\
\text { das tarefas }\end{array}$ & Em média de 31 minutos. Os usuários consideraram demasiado para um contato virtual. \\
\hline Autonomia de acesso & Apenas uma usuária com baixa visão não solicitou ajuda na execução das tarefas. \\
\hline
\end{tabular}

Como foi percebido, o portal da UAB para a realização de contato virtual não é acessível à pessoa com deficiência visual total, e difícil para quem possui baixa visão. Para os usuários, foi considerado pouco prático o acompanhamento da demanda por meio de senha, assim como listar as alternativas de informação no interior dos campos, pois o uso de símbolos como as setas, cores e asteriscos são visuais. Como os validadores e os usuários apontaram, neste quesito deveria haver um equivalente textual.

Já quanto aos problemas detectados no formulário de contato virtual, estes só puderam ser constatados com um nível mais preciso e elevado de detalhamento pela checagem humana. Esta também demonstrou a falta de consistência entre as páginas representativas. Na homepage, o link para a comunicação virtual com a UAB denomina-se Fale Conosco; enquanto na página seguinte está sob o rótulo de Universidade Aberta do Brasil - UAB. E, finalmente, intitulando o formulário, numa terceira página, há a expressão "Abertura de Demanda". Nesse sentido, o portal pode induzir o usuário à incompreensão, à perda de tempo acessando outros links e à desistência. Uma alternativa seria manter uma única expressão entre os links de contato virtual.

\section{DISCUSSÃO}

Com base nas avaliações executadas por ambos os métodos, uma análise comparativa entre os resultados permite algumas possíveis interpretações. Nesta direção, os dados provenientes dos validadores automáticos informam a expressiva incidência de Prioridade 1. A qual, sob uma ótica mais abrangente, indica que tais erros são inadmissíveis para qualquer 
organização que pretenda comunicar seus produtos e serviços com eficácia; e que objetiva conquistar o mercado de determinados grupos sub-representados para sua carteira de clientes. No caso da UAB, percebe-se uma incongruência entre fins e meios. Ou seja, o Programa objetiva expandir e interiorizar o ensino superior à distância pelo país. No entanto, não atenta para a questão da acessibilidade a todos os possíveis alunos de EaD em seu principal meio de comunicação, o portal. O que justifica uma avaliação na fase de projeto e durante a vida útil do portal.

Outro aspecto revelado pela comparação entre os dados corrobora o que Bach (2009) afirma acerca dos resultados advindos de validadores automáticos e de avaliação humana que podem ser divergentes. Pois, como pôde ser evidenciado, enquanto um dos validadores apontou como inacessível a homepage do portal, os usuários a consideram acessível. Porém, vale ressaltar que as tarefas estavam predeterminadas, uma das possíveis justificativas para o sucesso e rapidez na realização das mesmas pelos participantes. Isto, contudo, não significa que um acesso espontâneo por objetivos diversificados tivesse o mesmo resultado.

$\mathrm{Na}$ avaliação humana, a falta de autonomia dos participantes, dada à inacessibilidade do portal, pode levar à conclusão de que a pessoa com deficiência visual foi desconsiderada como provável usuária da web ou mesmo aluna de EaD; quando o mesmo foi criado em dissonância com os princípios inerentes à Educação à Distância e com os fins do programa UAB. Resultados estes corroborativos aos dados quantitativos fornecidos pelas ferramentas automáticas.

For fim, durante as entrevistas, os participantes expuseram a falta de conhecimento acerca da EaD e da UAB. O que para eles poderia ser uma modalidade alternativa de formação superior; tendo em vista ser a autoaprendizagem em tempo e lugar simultâneos e diferidos da instituição ensinante, de outros alunos e de professores uma das características mais contundentes da EaD, como pontua BELLONI (2009).

\section{CONCLUSÕES}

O presente trabalho teve como objetivo identificar possíveis problemas de acesso à informação no portal da UAB por meio de uma avaliação com a participação de pessoas com deficiência visual total e com baixa visão e por meio de dois validadores automáticos, o DaSilva e o Hera. Como os resultados indicaram, os usuários não conseguiram realizar o contato de modo autônomo devido aos problemas de acessibilidade no portal.

Desse modo, a avaliação confirma a necessidade de se consultar os usuários, como as pessoas com deficiência visual, para testarem o portal em sua fase de construção e durante a vida útil do mesmo. A acessibilidade à informação na web é um direito de todo cidadão que pode ser um primeiro passo ao exercício de outros como a educação superior. Este estudo, nesse sentido, vem a contribuir de modo prático, constatando a necessidade de haver reformulações no portal da UAB para que pessoas com deficiência visual acessem seu conteúdo com mais autonomia, 
ajustando-se melhor aos fins do Programa da UAB. Contribui, ainda, teoricamente, em demonstrar a importância de estudos dessa natureza com valores social e econômico. Pois, volta as pesquisas acadêmicas às demandas de grupos sociais sub-representados, considerando-os como alunos e cidadãos; assim como demonstra às organizações econométricas que tais grupos são usuários da Internet e consumidores.

A presente pesquisa teve por limitações a participação de pessoas com deficiência visual total e com baixa visão, tornando, assim, restrita à acessibilidade ao grupo. A partir dos achados, não se teve como pretensão generalizá-los devido ao peso dado ao caráter qualitativo aqui assumido na abordagem mista. Outro ponto relevante é o fato de ter sido estabelecido um roteiro de tarefas a serem executadas no portal da UAB não extinguindo, dessa forma, os vários problemas que uma avaliação dessa natureza pode ainda identificar.

No que tange ao uso de ferramentas de avaliação automática, optou-se por usar apenas dois validadores podendo ser avaliado ainda por outros como, por exemplo, o T.A.W., o AcessMonitor e tantas outras ferramentas de validação (consultar http://www.w3.org/WAl/ER/tools/complete), além de submeter às diretrizes da WCAG na versão 2.0 e/ou às diretrizes do Modelo de Acessibilidade do Governo Eletrônico (e-MAG).

Como a pesquisa concentrou-se em avaliar o contato virtual entre o usuário e a UAB, podem-se indicar estudos de acessibilidade, os quais estabeleçam outros roteiros de tarefas. Além da combinação entre validadores automáticos e usuários, existe a possibilidade de realizar outras avaliações com a participação de especialistas. Além dos usuários com deficiência visual, outros grupos como analfabetos funcionais, idosos e pessoas com limitações motoras podem integrar o teste de acessibilidade de websites.

\section{REFERÊNCIAS}

ALVES, M. A.; GALEÃO-SILVA, L. G.. A Crítica da Gestão da Diversidade nas Organizações. Revista de Administração de Empresas, São Paulo, v.44, n.3, p.20-29, 2004.

ARAÚJO, E. A.. Informação, Sociedade e Cidadania: gestão da informação no contexto de organizações não-governamentais (ONGs) brasileiras. Ciência da Informação, Brasília, v.29, n.2, p.155-167, 1999.

BABU, R., SINGH, R. GANESH, J.. Understanding Blind Users' Web Accessibility and Usability Problems. AIS Transactions on Human-Computer Interaction, v.2, n.3, p.73-94, 2010.

BACH, C. F.. Avaliação de acessibilidade na web: estudo comparativo ente métodos de avaliação com a participação de deficientes visuais. Dissertação (Mestrado em Informática) - Universidade Federal do Estado do Rio de Janeiro, Rio de Janeiro, 2009.

BACH, C. F.; FERREIRA, S. B.; SILVEIRA, D. S.. Avaliação da acessibilidade na web: estudo comparativo entre métodos de avaliação com a participação de deficientes visuais. In: ENCONTRO ANUAL DA ASSOCIAÇÃO DE PÓS-GRADUAÇÃO E PESQUISA EM ADMINISTRAÇÃO, 33. Anais. São Paulo: Hotel Transamérica, 2009. CD-ROM.

BARBOSA, S. D. J.; SILVA, B. S.. Interação humano-computador. Rio de Janeiro: Elsevier, 2010.

BAR-ILAN, J.; KEENOY, K.; LEVENE, M.; YAARI, E.. Presentation Bias is Significant in Determining User Preference for Search Results: A User Study. Journal of the American Society for Information Science and Technology, v.60, n.1, p.135-149, 2009. 
BELLONI, M. L.. Educação à distância. 5 ed. São Paulo: Autores Associados, 2009.

BRASIL. CAPES. Universidade Aberta do Brasil. Brasília, 2012.

BRASIL. Decreto ${ }^{\circ} \mathbf{5 . 2 9 6}$ de 02 de dezembro de 2004. Regulamenta as Leis nos 10.048 , de 8 de novembro de 2000, que dá prioridade de atendimento às pessoas que especifica, e 10.098, de 19 de dezembro de 2000, que estabelece normas gerais e critérios básicos para a promoção da acessibilidade das pessoas portadoras de deficiência ou com mobilidade reduzida, e dá outras providências. Brasília, 02 Dez 2004.

BRASIL. IBGE. Censo demográfico. Brasil, IBGE, 2010.

CAPRA, E. P.; FERREIRA, S. B. L.; SILVEIRA, D. S.; RIBEIRO, B. B.. Avaliação da Acessibilidade Web sob a Perspectiva do Analfabetismo Funcional. In: ENCONTRO DE ADMINISTRAÇÃO DA INFORMÁTICA, 3. Anais. Porto Alegre, 2011. CD-ROM.

CEPIK, M. A. C.. Direito à Informação: situação legal e desafios. Informática Pública, n.4, p.43-56, 2000.

CRESWELL, J. W.. Projeto de Pesquisa: métodos qualitativo, quantitativo e misto. Porto Alegre: Artmed. 2010.

FERREIRA, S. B. L.; NUNES, R.. e-Usabilidade. Rio de Janeiro: LTC. 2008.

FLEURY, M. T. L.. Gerenciando a Diversidade Cultural: experiências de empresas brasileiras. Revista de Administração de Empresas, São Paulo, v.40, n.3, p.18-25, 2000.

FLICK, U.. Introdução à pesquisa qualitativa. Porto Alegre: Artmed, 2009.

FREIRE, A. P.. Acessibilidade no Desenvolvimento de Sistemas Web: um estudo sobre o cenário brasileiro. Dissertação (Mestrado em Ciências da Computação e Matemática Computacional) Universidade de São Paulo, São Carlos, 2008.

JAEGER, P.. Multi-method evaluation of $u$. s. federal electronic government websites in terms of accessibility for persons with disabilities. Dissertation (Doctor of Philosofhy) - Florida State University, Florida, 2006.

LIMA, C. S. P. C.; FERREIRA, S. B.; SILVEIRA, D. S.. A avaliação da acessibilidade de sistemas de comunicação com a participação de pessoas com deficiência visual total. In: ENCONTRO ANUAL DA ASSOCIAÇÃO DE PÓS-GRADUAÇÃO E PESQUISA EM ADMINISTRAÇÃO, 34. Anais. Rio de Janeiro: Windsor Barra Hotel e Congressos, 2010. CD-ROM.

MAIA, C.; MATTAR, J.. ABC da EAD: a educação à distância hoje. São Paulo: Pearson Prentice, 2007.

NIELSEN, J.. Usability Engineering. California: Morgan Kaufmann, 1993.

SANTAROSA, L. M. C.; PASSERINO, L.; BASSO, L. O.; DIAS, C. O.. Acessibilidade em ambientes de aprendizagem por projetos: construção de espaços virtuais para inclusão digital e social de PNEEs. Novas Tecnologias na Educação, v.5, n.1, p.1-11, 2007.

SANTOS, A. I.. O conceito de abertura em EAD. In: LITTO, F. M.; FORMIGA, M. M. M.. Educação à distância: o estado da arte. São Paulo: Pearson, 2009. p.290-296.

SILVEIRA, D. S.; SILVEIRA, M. A. A.; ANDRADE, S. R. P.; CUNHA, G. R.; FERREIRA, A. R.. Acessibilidade de informações em portais governamentais para deficientes visuais: o caso da Receita Federal do Brasil. In: ENCONTRO NACIONAL DE PESQUISA EM CIÊNCIA DA INFORMÁTICA, 11. Anais. Rio de Janeiro: CPRM, UNIRIO, 2010. CD-ROM.

VERGARA, S. C.; IRIGARAY, H. A. R.. Os múltiplos discursos sobre diversidade no ambiente de trabalho. In: ENCONTRO ANUAL DA ASSOCIAÇÃO DE PÓS-GRADUAÇÃO E PESQUISA EM ADMINISTRAÇÃO, 31. Anais. Rio de Janeiro: Windsor Barra Hotel e Congressos, 2007. CD-ROM. 